\title{
Two new xanthones from Artocarpus obtusus
}

\begin{abstract}
Two new xanthones, pyranocycloartobiloxanthone A (1) and dihydroartoindonesianin C (2), were isolated from the stem bark of Artocarpus obtusus Jarrett by chromatographic separation. Their structures were determined by using spectroscopic methods and comparison with known related compounds. Pyranocycloartobiloxanthone A (1) showed strong free radical scavenging activity by using DPPH assay as well as cytotoxicity towards K562, HL-60, and MCF7 cell lines.
\end{abstract}

Keyword: Artocarpus obtusus; Moraceae; pyranocycloartobiloxanthone A; dihydroartoindonesianin C; cytotoxicity 